\title{
The Effect of Polyurea Mass Ratio on the Acceleration Mitigation Capabilities of Dynamically Loaded Structures
}

\author{
Jarrod Bonsmann • W. L. Fourney
}

Received: 9 December 2014 / Accepted: 12 January 2015/Published online: 31 January 2015

(C) Society for Experimental Mechanics, Inc 2015

\begin{abstract}
This research investigates the acceleration mitigation effect that polyurea coatings have on dynamically loaded structures. In order to complete this study high-pressure gas guns and small explosives experimentation was conducted. The explosives designated for this research are exclusively buried in saturated sand, which serves as the loading mechanism for those experiments. Cantilevered beams are used in conjunction with the gas gun while cylindrical plates were the chosen apparatus for the explosive experiments. Piezoelectric accelerometers are used in conjunction with high-speed videography to collect experimental data. At the conclusion of the research it was determined that polymeric coatings were beneficial in mitigating acceleration resulting from explosive loading and for dynamically loaded beams. The effects in both cases depend greatly on the amount of polyurea (mass ratio of polyurea to metal) applied to the metallic structure.
\end{abstract}

Keywords Acceleration mitigation $\cdot$ Polyurea $\cdot$ Dynamic loading

\section{Introduction}

Over the past decade, the increase in fatalities due to use of buried explosives has created a demand for expanded knowledge in the field of target response to blast loading. When a vehicle experiences a blast load from a buried explosive, it is speculated that the damage mechanisms for a passenger in the vehicle result from rapid accelerations

J. Bonsmann $(\bowtie) \cdot$ W. L. Fourney

Dynamic Effects Laboratory, University of Maryland,

College Park, USA

e-mail: bonsmann@umd.edu
[1] and large changes in momentum [2]. Blast loading results in traumatic brain injury (TBI) and violent injuries such as broken limbs due to rapid accelerations and large changes in momentum. In recent years a growing number of people involved in buried explosive attacks have been diagnosed with TBI in what is speculated to have resulted from the rapid acceleration of the targeted vehicle.

The Dynamic Effects Lab at the University of Maryland has spent considerable time and resources investigating the dynamic response of structures to high-speed loading. Research has been conducted to better understand the mechanisms of the blast loading on vehicles [3] and to determine various methods of reducing impulse and acceleration on them $[4,5]$. The main mechanism of vehicle loading for a buried charge is the impact on the vehicle bottom by the soil that is thrown up by the detonated charge. This soil has been shown to be traveling in excess of Mach one, and when it is brought to rest on the bottom of the vehicle very large pressures develop [6].

By shaping the bottom of the vehicles, violent injuries and deaths due to the change in the impulse have steeply declined. However, since the passenger of the vehicle is surviving beyond the initial blast, the incidences of injury (including TBI) have risen. For this reason, further knowledge is needed in the area of acceleration mitigation on blast loaded vehicles.

One of the primary focuses in this paper is to study the acceleration mitigation effects of localized buckling (crushing) of thin-walled cylinders which have been coated with polyurea. Thin-walled cylinders have long been studied in the field of energy absorption. There exists a plethora of research detailing the benefits of adding tubes to structures to absorb impact energy. For lower speed impacts both Alghamdi and Yuen et al. give an overview of a multitude of collapsible structures for use as energy absorbers [7, 8]. 
A number of studies have been performed characterizing the benefits of crushing tubes laterally for impact protection $[9,10]$. Quite a few studies have been conducted to classify the energy absorption of composite tubes [11-13]. Additionally there have even been some studies, both numerical and experimental, where tubes or thin-walled structures of multiple geometries made of various materials (both metallic and composite) have been studied for use as sacrificial claddings for structures that undergo blast loading [14-16]. All of this research points to the fact that thinwalled structures, in a variety of geometrical patterns made of all kinds of materials, have numerous benefits to offer when it comes to protecting structures from blast loads. There is a dearth of information, however, involving the benefits of using thin-walled cylinders coated with polyurea as a technique for mitigating acceleration.

Considerable effort has been spent $[17,18]$ in researching the mechanical behavior of polymeric materials used for coatings in blast applications, especially the material polyurea. It has been found that under very high strain rates the polymer loses its "rubbery" mechanical behavior and begins to act more like leather. This characteristic allows the polymer to increase toughness under high strain rates, making it more effective at absorbing blast loads. In addition to characterizing the high strain rate mechanical properties of polyurea, the polymeric coating has been applied to panels that undergo blast loading in order to determine what benefits it has as a protective layer to prevent deformation and damage to structures. Major benefits in the protection of structures due to polymeric or elastomeric coatings have been found when applied to composite structures [19, 25, 26]. On the contrary, when applied to steel plates (keeping the areal density constant) it was found that plain steel plates absorb the blast more effectively than those coated with polyurea [20]. Finally, some preliminary work has been performed in previous years in the Dynamic Effects Lab that shows that coating the hull of a vehicle (with polyurea) that undergoes blast loading is an effective means for acceleration mitigation, though it should be noted that the areal density was not kept constant in this study [21].

This paper will investigate two different means of acceleration mitigation of metallic structures with polyurea coatings. Initially, a high-pressure gas gun will be used to dynamically load a series of cantilevered beams with varying thicknesses of polyurea coatings. This study will be extended by keeping the mass of the beam constant while varying the mass ratio of the polyurea to the metal substrate. Additionally, polyurea coatings will be applied to thin-walled cylinders that are crushed between a set of explosively loaded plates. Various mass ratios of polyurea to metallic substrate of the cylinders will be examined. Furthermore a study is conducted that will look at the nonlinearity of the mitigation benefit of polyurea coatings employed in this manner. At the conclusion of the research it was determined that polymeric coatings were beneficial in mitigating acceleration resulting from explosive loading and for dynamically loaded beams. The effects in both cases depend greatly on the amount of polyurea (mass ratio of polyurea to metal) applied to the metallic structure.

\section{Experimental Methods}

\section{Cantilevered Beam Experiments}

Two types of experiments were run during this research series. Initially, beams coated with polyurea were tested dynamically to develop a basic understanding of the acceleration mitigation effects of polyurea coatings. Cantilevered beams coated in polyurea were tested using a highpressure gas gun to provide the loading. Beams with varying thicknesses and mass ratios of polyurea were studied.

The cantilever beam experiments are set-up by first placing a beam in the cantilever support. Care is taken to place the center of the beam in line with the projectile path. The beam is clamped such that it cannot move in the support, thus providing a true cantilever end condition. Each experimental beam is $25.4 \mathrm{~cm}$ long with the first $2.54 \mathrm{~cm}$ being secured in the cantilever clamp. Each beam is placed such that the projectile fired from the gas gun hits the tip of the beam in the center of the beam width so that the beam undergoes minimal twist upon impact.

A Phantom v12.1 high-speed camera equipped with a Tamron $28-75 \mathrm{~mm}$ variable focus lens was used to track the motion of the loaded beams. The video was analyzed with the Phantom software. Microsoft Excel was used to create displacement versus time plots.

In addition to being viewed by a high-speed camera, each experiment was conducted with an accelerometer mounted to the end of the beam for data collection purposes. The accelerometer used in this series of experiments was manufactured by PCB Piezotronics Inc (model 350B04 with a measurement range of $\pm 5,000 \mathrm{~g}$ ). The axis of the accelerometer is placed $2.54 \mathrm{~cm}$ below the tip of the beam. By mounting the accelerometer in a rubber sleeve as shown in Fig. 1, the accelerometer is on the neutral axis of the beam and is subjected to minimum transverse motion during the experiment. A PCB Piezotronics Inc. signal conditioner, model 483A and two LeCroy oscilloscopes, model numbers 9314AM and 9315AM, were employed with the accelerometer for data acquisition. A photograph of the final beam configuration is seen in Fig. 1.

Once the beam has been placed in the testing position, the gas gun projectile is loaded and the pressure chamber primed. For the beam experiments the pressure is in the neighborhood of 75 kilopascals. For each experiment the 
Fig. 1 Beam set-up for cantilever beam experiments

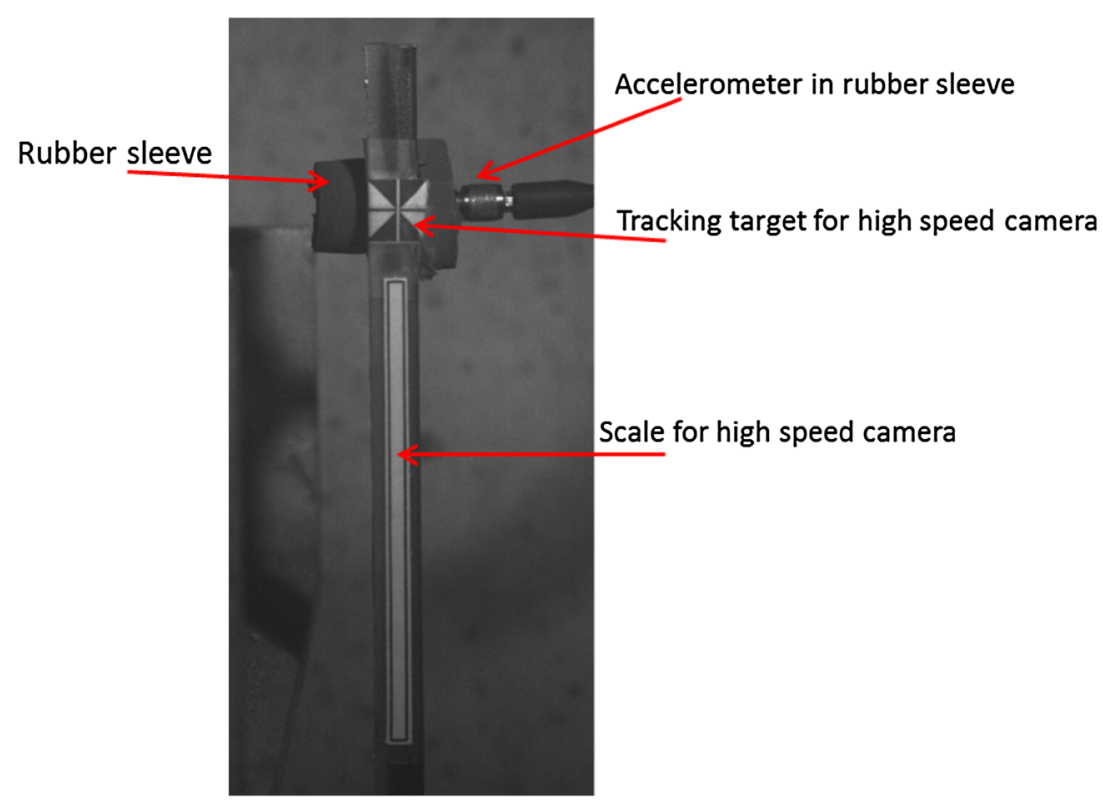

projectile is tracked for one inch of travel using high-speed video. The slope of the displacement versus time curve for the projectile is used to find its velocity for each experiment, and must be in the range of $8.4-8.6 \mathrm{~m} / \mathrm{s}$ in order for the data to be accepted. Once the gun is pressurized, the oscilloscopes and high-speed camera are made ready and are triggered simultaneously by the firing of the gas gun. The data is then downloaded from the oscilloscopes and saved for processing.

The displacement curves determined from the accelerometer (by double integration) and from the high-speed camera are compared after every experiment. In order for experimental results to be reported, the displacement versus time curves developed from the double integrated accelerometer data and the high-speed camera must closely match. An acceptable level of correspondence is shown in Fig. 2.

The polyurea used for this research was manufactured by Specialty-Products, Inc. and is designated HM-VK. It is an ultra-high strength hand-mixable polyurea elastomer. This specific polyurea was chosen for its high gel-time of $18 \mathrm{~min}$ and lower viscosity. These two properties allow the polyurea to be used in a mold to accurately create test specimens for this study. A description of the properties of the polyurea when dry (as obtained from the HM-VK technical data sheet) is shown in Table 1.

\section{Blast-Loaded Cylinder Experiments}

The second set of experiments run was aimed at understanding how polyurea coating could be applied to a previously proven acceleration mitigation technique [22] to

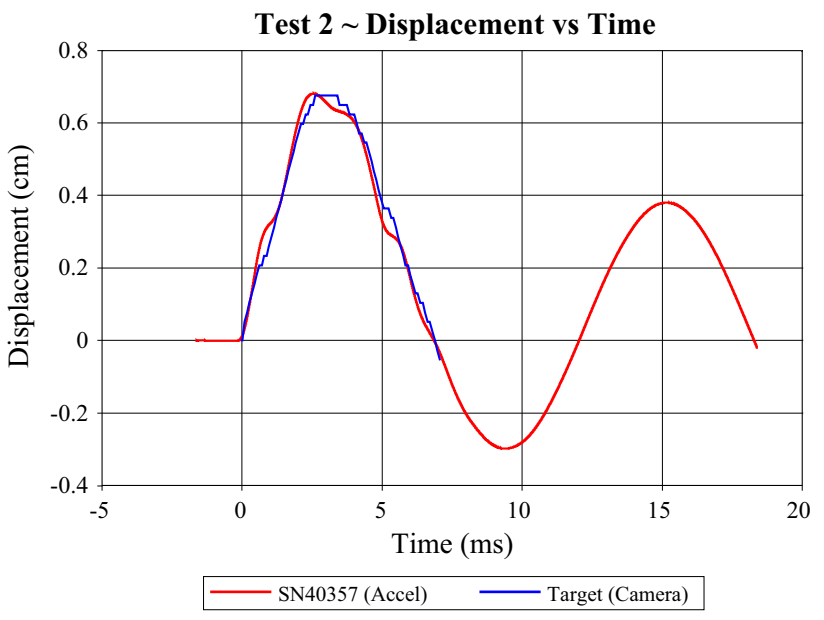

Fig. 2 Example of a displacement versus time comparison for rubber mounted accelerometer (double integrated) when compared to highspeed video results

enhance the mitigation benefit. Specifically, polyurea coatings were applied to thin-walled cylinders that were crushed between a set of explosively loaded plates. This series of experiments utilized a single thin-walled cylinder in between two circular aluminum plates. The aluminum plates are termed the hull (bottom) and the frame (top). The plate characteristics are listed in Table 2.

The thin-walled cylinder was created from aluminum shim stock with a polyurea coating applied onto the outer walls. A specific mass of polyurea for each experiment is mixed and applied to the prepared shim stock surface using a small paint brush. The low viscosity of the polyurea allowed for the material to settle on the surface of the metal 
Table 1 Polyurea dry properties for HM-VK [24]

\begin{tabular}{ll} 
Dry properties @ 125 mils $(1.67 \mathrm{~mm})$ & \\
\hline Tensile strength ASTM D412 & $6671 \mathrm{PSI}(46.36 \mathrm{mpa})$ average \\
Elongation ASTM D412 & $506 \%$ average \\
Hardness (Shore A) ASTM D2240-81 & $95(0 \mathrm{~s})$ \\
Hardness (Shore D) ASTM D2240-81 & $48(0 \mathrm{~s})$ \\
Modulus 300 \% ASTM D412 & $1395 \mathrm{psi}(9.7 \mathrm{mpa})$ \\
Service temperature & -30 to $+250{ }^{\circ} \mathrm{F}\left(-34\right.$ to $\left.+121^{\circ} \mathrm{C}\right)$ \\
\hline
\end{tabular}

Table 2 Polyurea coated cylinder test plate characteristics

\begin{tabular}{|c|c|c|c|c|c|c|c|c|}
\hline $\begin{array}{l}\text { Frame } \\
\text { material }\end{array}$ & $\begin{array}{l}\text { Frame } \\
\text { diameter }(\mathrm{cm})\end{array}$ & $\begin{array}{l}\text { Frame } \\
\text { thickness }(\mathrm{cm})\end{array}$ & $\begin{array}{l}\text { Frame mass w/targets } \\
\text { and accels }(\mathrm{kg})\end{array}$ & Hull material & $\begin{array}{l}\text { Hull } \\
\text { diameter }(\mathrm{cm})\end{array}$ & $\begin{array}{l}\text { Hull thickness } \\
(\mathrm{cm})\end{array}$ & $\begin{array}{l}\text { Hull mass } \\
(\mathrm{kg})\end{array}$ & $\begin{array}{l}\text { Total plate } \\
\text { mass }(\mathrm{kg})\end{array}$ \\
\hline Alum 6061 & 16.51 & 2.74 & 1.43 & Alum 6061 & 16.51 & 2.82 & 1.27 & 2.74 \\
\hline
\end{tabular}

and create a more or less uniform coating thickness (disregarding the very edge). Each experiment was conducted with a pre-determined mass ratio of polyurea to the aluminum substrate. The thin-walled cylinder in each experiment was connected to the hull only, and the frame was equipped with four targets for high-speed video tracking and two accelerometers. A sample test plate is seen in Fig. 3.

To create the blast, plastic explosive sheet (Deta Sheet from Omni Explosives) was used in conjunction with an Exploding Bridge Wire Detonator manufactured by Teledyne Technologies. The detonator has a small amount of explosive located inside of it that, when combined with the plastic Deta sheet, sums up to a total mass of explosive reported for each experiment (unless otherwise specified, the charges used in this series of experiments had a mass of $2.2 \mathrm{~g}$ ). The plastic explosive charge is formed and placed in a plastic sleeve to insure repeatability in charge geometry from experiment to experiment. The firing system responsible for detonation is connected to the explosive, the high-speed camera, and the oscilloscopes so that when the firing system is discharged all of the recording devices trigger at the same time to record the explosive event.
The actual blast experiment takes place in a tank constructed to outer dimensions of $1.5 \mathrm{~m}$ long by $1.5 \mathrm{~m}$ wide by $0.6 \mathrm{~m}$ deep. The tank is filled with sand and is capable of being flooded with water from the bottom. A schematic of the blast testing equipment is shown in Fig. 4.

There are a number of steps that must be taken in order to prepare for each blast experiment. Because of the small-scale nature of the test, experiment preparation is performed with the utmost care as a small variation in any value may result in large variation in the experimental results. Each of the steps mentioned in the next paragraph are explained in more detail in another paper [23].

The initial sand bed preparation consists of creating a 1.2 meter by 1.2 meter elevated and compacted sand platform in the center of the test bed. The height and compaction of the sand bed is controlled and repeatable. Once created, the explosive charge is buried in the sand platform at a location directly under the center of any specific test plate. For all of the experiments in this study a $10 \mathrm{~mm}$ depth of burial (DOB) is used. DOB is defined here as the distance between the top surface of the charge and the surface of the sand.
Fig. 3 Accelerometer placement (left) and plate set-up (right) for coated can experiments
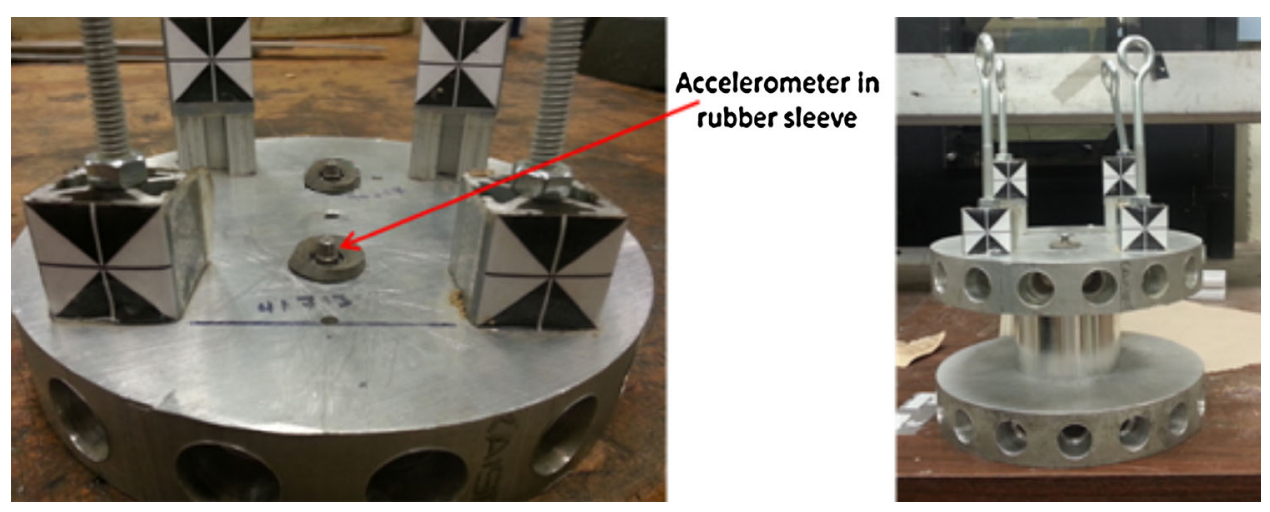


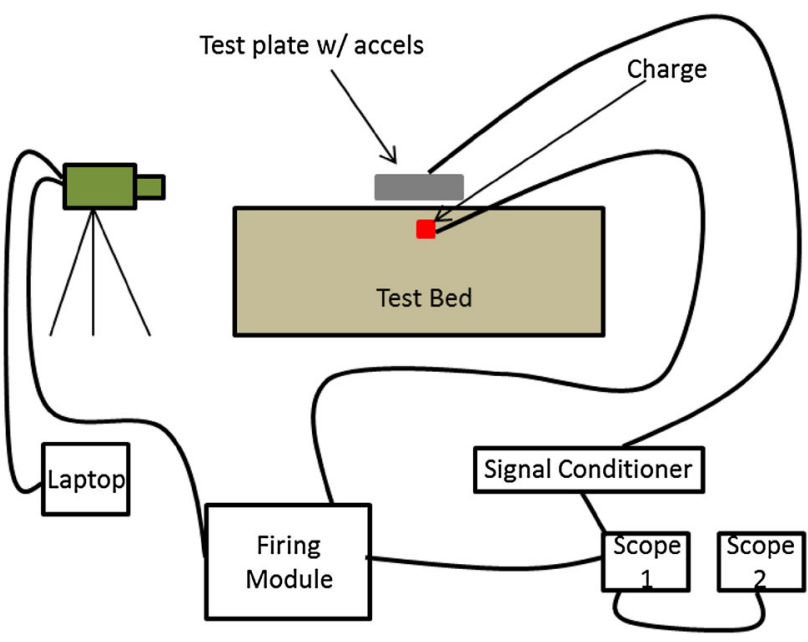

Fig. 4 Schematic detailing blast test equipment set-up

The next step was to locate the plate and establish its stand-off distance (SOD). SOD is defined as the distance between the top of the sand and the bottom of the test plate. The test plate is placed on a set of blocks that are machined to $40 \mathrm{~mm}$ in height, thus establishing a $40 \mathrm{~mm}$ SOD (Fig. 5). Once prepared, the test bed is saturated from the bottom up. The water height is controlled and repeatable. The final test set-up for a typical blast experiment is shown in Fig. 5.

Once the bed has saturated fully, the accelerometer cables are connected to each accelerometer on the plate. The high-speed camera is set-up and the image adjusted, following which a dummy charge is fired to make sure all data acquisition systems are functioning properly. After the dummy round, the charge lead wires are connected to the firing module and the charge is detonated. Upon detonation the video is examined and saved using the Phantom software. The acceleration signal is downloaded from the scopes and viewed in the UERD Tools (software developed by NSWC-Carderock Division) to ensure proper recording; the signals are then saved and analyzed.

\section{Experimental Results}

\section{Cantilevered Beam Results}

Before going into the results for each specific series of experiments for the polyurea coated beams, it is necessary to specify how each beam was placed in the cantilever support with relation to the oncoming projectile. A number of arrangements were investigated to determine which face of the bar (the metal side or the polyurea side) should be struck with the projectile. Three different situations were examined: projectile contacting the steel (polyurea in compression), projectile contacting the polyurea (polyurea in tension), and the polyurea at the area of contact ground off so that the projectile contacted the steel but still put the polyurea in tension. The three situations are illustrated in Fig. 6.

Only the peak acceleration will be reported for each experiment. The acceleration results for the beam for the three scenarios portrayed in Fig. 6 are displayed in Fig. 7. Each configuration was run twice to determine data scatter. The blue bars show the values for the initial experiments and the red bars give the value for the repeat experiment for each case.

From looking at Fig. 7 it is noted that orientation has an effect on acceleration. A reduction in peak acceleration results from the bar being placed so that upon initial deflection of the beam, the polyurea is put into tension. There does not appear to be any effect from the polyurea at the tip of the beam being removed, resulting in a projectile to steel interaction. As such, all of the cantilevered beam experiments that followed were conducted with the
Fig. 5 Fully prepared blast test sand bed

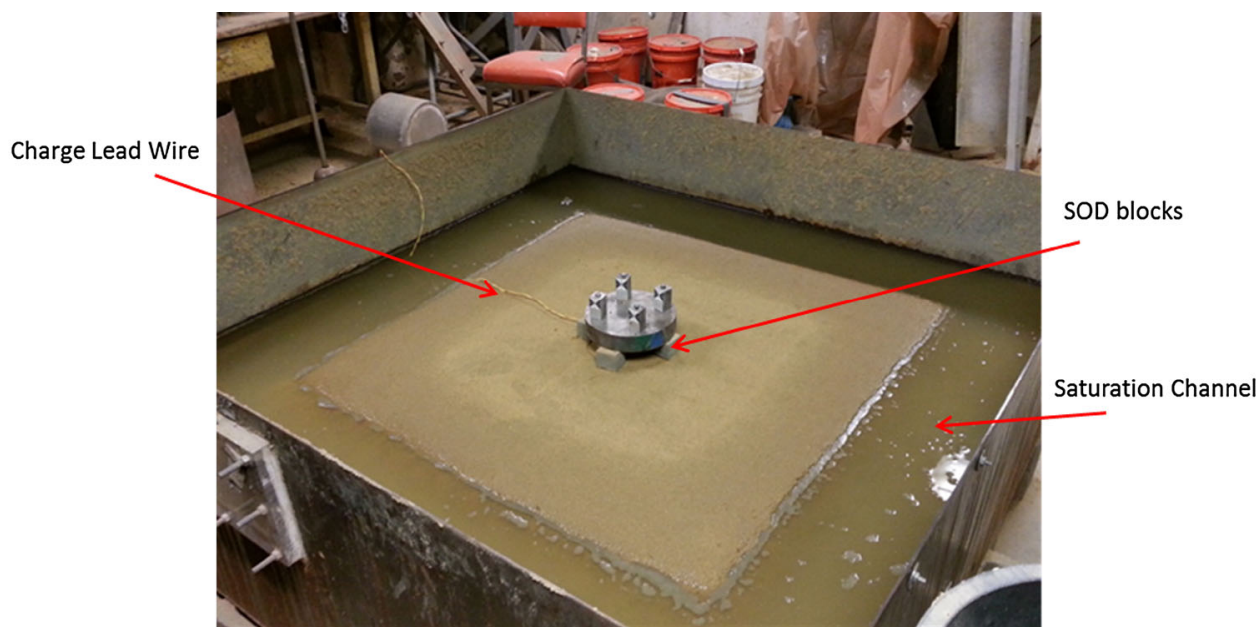


Fig. 6 Contact configuration for preliminary polyurea experiments

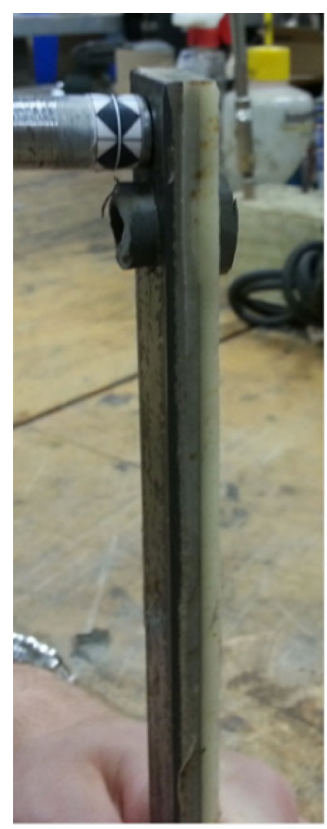

Steel side contact

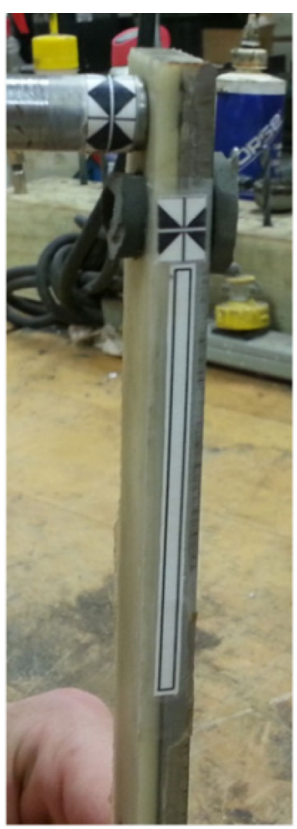

Polyurea side contact

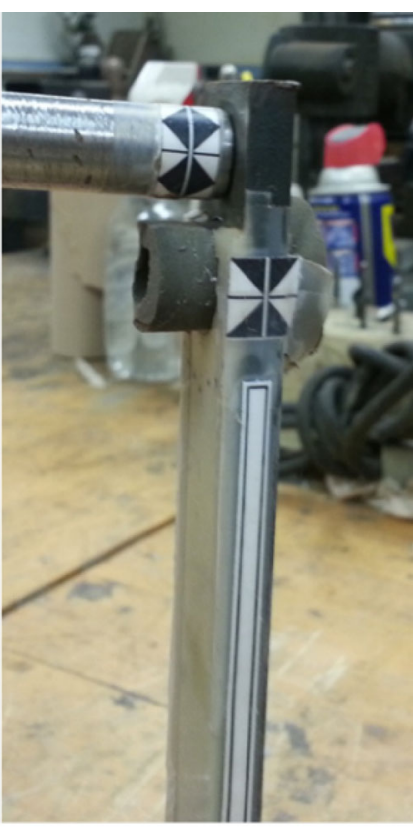

Steel contact on polyurea side
Fig. 7 Peak acceleration for preliminary polyurea beam experiments

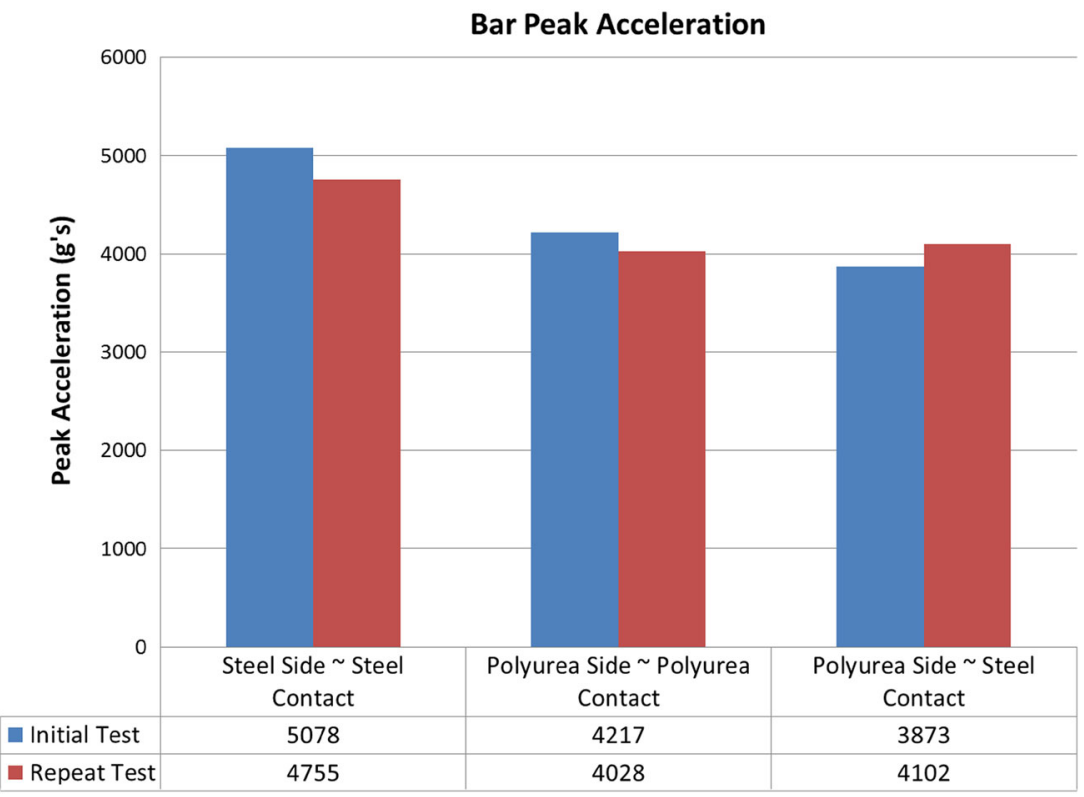

polyurea side facing the projectile, without removing the polyurea from the tip of the beam.

The first series of experiments run for polyurea coated bars studied the effects of increasing polyurea thicknesses on steel beams of the same outer dimensions. Baseline tests were run with two different bare steel beams to determine the variance in behavior for two different beams of steel cut from the same bar. After these initial experiments, three different thicknesses of polyurea were applied to steel beams and tested. Table 3 gives the information for each of the experiments conducted in this series with steel beams. Each experiment was conducted twice to determine data scatter and repeatability.

Additionally a set of experiments was conducted where the mass of each specimen was kept constant as the polyurea mass increased. This was accomplished by using a mill to shave specific thicknesses of metal off of the steel beams. A polyurea coat having the same mass as the removed steel was then applied to each beam. The mass of each beam was kept at the mass of the baseline beam from 
Table 3 Test matrix for general polyurea thickness study

\begin{tabular}{|c|c|c|c|c|c|c|c|}
\hline $\begin{array}{l}\text { Test } \\
\text { number }\end{array}$ & $\begin{array}{l}\text { Bar } \\
\text { number }\end{array}$ & Steel mass (g) & $\begin{array}{l}\text { Polyurea } \\
\text { mass (g) }\end{array}$ & $\begin{array}{l}\text { Total mass } \\
\text { (w/accel) (g) }\end{array}$ & $\begin{array}{l}\text { Bar thickness } \\
(\mathrm{mm})\end{array}$ & $\begin{array}{l}\text { Polyurea } \\
\text { thickness (mm) }\end{array}$ & Mass ratio \\
\hline 4 & 3 & 302.6 & 0 & 314.1 & 6.22 & 0.00 & 0.00 \\
\hline 6 & 3 & 302.6 & 0 & 314.1 & 6.22 & 0.00 & 0.00 \\
\hline 8 & 1 & 300.3 & 0 & 312.5 & 6.20 & 0.00 & 0.00 \\
\hline 9 & 1 & 300.3 & 0 & 312.5 & 6.20 & 0.00 & 0.00 \\
\hline 17 & 2 & 301.5 & 12.6 & 326.8 & 6.23 & 1.58 & 0.04 \\
\hline 18 & 2 & 301.5 & 12.6 & 326.8 & 6.23 & 1.58 & 0.04 \\
\hline 24 & 1 & 300.3 & 18.3 & 329.7 & 6.20 & 3.11 & 0.06 \\
\hline 25 & 1 & 300.3 & 18.3 & 329.7 & 6.20 & 3.11 & 0.06 \\
\hline 27 & 3 & 302.6 & 21.4 & 334.6 & 6.22 & 4.76 & 0.07 \\
\hline 28 & 3 & 302.6 & 21.4 & 334.6 & 6.22 & 4.76 & 0.07 \\
\hline
\end{tabular}

the first series of experiments. The experiments were run in the same manner as the previous series of experiments. The matrix of experiments is seen in Table 4. The results showing how peak acceleration of the beam tip varies with increased mass ratio is shown in Fig. 8.

The figure above shows an unexpected result. The peak acceleration of the bars coated in polyurea increased with mass ratio for both the case where the total mass of the beam increased, and the case where it was held constant. This increase is on the order of the magnitude of the change in acceleration that resulted (in the preliminary tests) from placing the polyurea coated side initially in tension versus initially in compression.

At the same time that these experiments were being conducted, we were also looking at the effects of coating thin-walled crushing cylinders on accelerations (which will be presented later in this paper) and had found that coating the cylinders with polyurea resulted in a noticeable reduction in accelerations. In those experiments the mass ratios of polyurea to metal were much higher than in the experiments that were just presented (ratios in the range of one through five rather than the maximum of 0.15 as just reported). In hopes of clarifying this result, a final series of cantilever beam experiments were carried out. To create a more equivalent series of experiments, it was necessary to process cantilever beams with a mass ratio closer to those of the crushing cylinders.

Beams were created by decreasing the mass of the metal base of the beam by switching the metal from steel to aluminum, and also by decreasing the thickness of the metal from 6.2 to $3.18 \mathrm{~mm}$. An uncoated beam was tested in addition to two beams with mass ratios in the desired range. The test matrix can be seen in Table 5. Each beam configuration was tested twice to determine data scatter and repeatability and the results are plotted in Fig. 9.

From viewing the previous figure and comparing it with the trends developed in the steel cantilevered beam tests, it is apparent that a completely different trend has emerged.

Table 4 Test matrix for polyurea beam mass study

\begin{tabular}{|c|c|c|c|c|c|c|c|c|}
\hline $\begin{array}{l}\text { Test } \\
\text { number }\end{array}$ & $\begin{array}{l}\text { Bar } \\
\text { number }\end{array}$ & $\begin{array}{l}\text { Steel } \\
\text { mass }(\mathrm{g})\end{array}$ & $\begin{array}{l}\text { Polyurea } \\
\text { mass (g) }\end{array}$ & $\begin{array}{l}\text { Total mass (w/ } \\
\text { accel) }(\mathrm{g})\end{array}$ & $\begin{array}{l}\text { Mass ratio } \\
\text { (polyurea/steel) }\end{array}$ & $\begin{array}{l}\text { Bar thickness } \\
(\mathrm{mm})\end{array}$ & $\begin{array}{l}\text { Polyurea } \\
\text { thickness (mm) }\end{array}$ & $\begin{array}{l}\text { Total thickness } \\
(\mathrm{mm})\end{array}$ \\
\hline $\mathrm{a}$ & 3 & 302.6 & 0 & 314.1 & 0.000 & 6.22 & 0 & 6.22 \\
\hline $\mathrm{b}$ & 3 & 302.6 & 0 & 314.1 & 0.000 & 6.22 & 0 & 6.22 \\
\hline $\mathrm{c}$ & 1 & 300.3 & 0 & 312.5 & 0.000 & 6.20 & 0 & 6.20 \\
\hline $\mathrm{d}$ & 1 & 300.3 & 0 & 312.5 & 0.000 & 6.20 & 0 & 6.20 \\
\hline 12 & 6 & 281.8 & 23.4 & 316 & 0.083 & 5.88 & 3.49 & 9.37 \\
\hline 15 & 6 & 281.8 & 23.4 & 316 & 0.083 & 5.88 & 3.49 & 9.37 \\
\hline 17 & 4 & 273.9 & 25.8 & 310.2 & 0.094 & 5.68 & 4.33 & 10.01 \\
\hline 18 & 4 & 273.9 & 25.8 & 310.2 & 0.094 & 5.68 & 4.33 & 10.01 \\
\hline 19 & 5 & 265.2 & 37.8 & 313.8 & 0.143 & 5.46 & 5.88 & 11.34 \\
\hline 20 & 5 & 265.2 & 37.8 & 313.8 & 0.143 & 5.46 & 5.88 & 11.34 \\
\hline 21 & 5 & 265.2 & 37.8 & 313.8 & 0.143 & 5.46 & 5.88 & 11.34 \\
\hline
\end{tabular}


Fig. 8 Trend showing the variation of peak acceleration of the cantilever beam with increasing mass ratio of polyurea to steel with constant and non-constant total mass

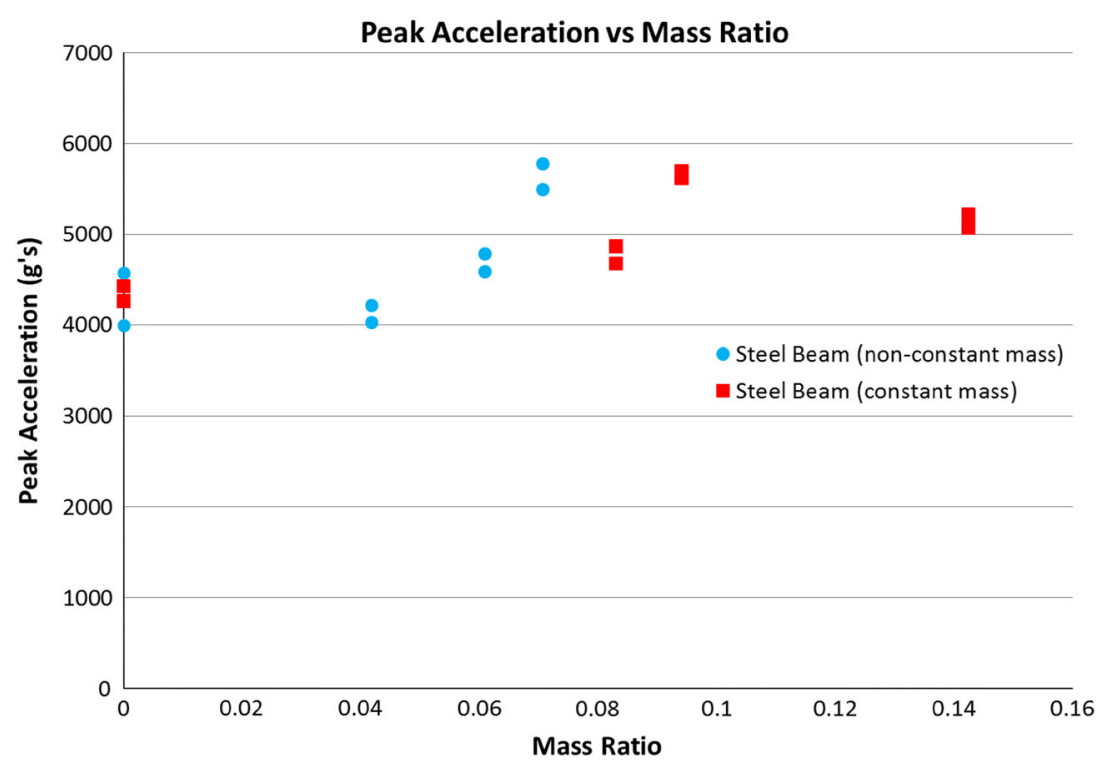

Whereas the beams with a mass ratio much less than one see increases in the peak acceleration, the beams with greater mass ratios result in decreases in accelerations.

\section{Blast-Loaded Cylinder Results}

The next series of experiments run involved crushing thinwalled cylinders between explosively loaded plates. Before describing the results for this study it should be noted that this series of experiments aims only at describing the differences in acceleration of the frame that arise from coating thin-walled cylinders with polyurea. An expansion of the results from the use of crushing cylinders (both coated and uncoated) are presented in another paper [22]. The variable that changed and is reported here is the mass ratio of polyurea applied to the metallic thin-walled cylinder. The test matrix for this study is seen below in Table 6 .

Similar to the beam experiments, the initial test for data validity is the comparison of the displacement curve developed from the tracking of the targets using high-speed video with that of the double integrated acceleration signal. It should be mentioned that due to the small size and weight of the test plate, slight offsets in charge location or plate placement resulted in some rotation of the frame. As such the accelerometer displacement was plotted along with all four target displacement curves to make sure it fell among them. Samples of the acceleration signal along with the displacement curve comparison are shown in Figs. 10 and 11. The displacement signals from the high-speed camera and the accelerometer match very nicely. This same level of agreement is required for the experimental results to be considered valid.

Another area of interest is viewing how the acceleration signal changes with the increasing mass of polyurea applied to the thin-walled cylinder. To this end a sample signal from one accelerometer for the four experimental scenarios is plotted on the same graph. The result is shown in Fig. 12.

From studying Fig. 12 a couple of observations can be made. The first and most obvious is how the peak

Table 5 Test matrix for equivalent mass ratio cantilever beam study

\begin{tabular}{lllllllll}
\hline $\begin{array}{l}\text { Test } \\
\text { number }\end{array}$ & $\begin{array}{l}\text { Beam } \\
\text { number }\end{array}$ & $\begin{array}{l}\text { Aluminum beam } \\
\text { thickness (mm) }\end{array}$ & $\begin{array}{l}\text { Aluminum } \\
\text { beam mass (g) }\end{array}$ & $\begin{array}{l}\text { Polyurea } \\
\text { thickness (mm) }\end{array}$ & $\begin{array}{l}\text { Polyurea } \\
\text { mass (g) }\end{array}$ & $\begin{array}{l}\text { Beam } \\
\text { length } \\
(\mathrm{cm})\end{array}$ & $\begin{array}{l}\text { Beam total mass } \\
\text { w/accel (g) }\end{array}$ & $\begin{array}{l}\text { Polyurea/steel } \\
\text { mass ratio }\end{array}$ \\
\hline 1 & 1 & 3.18 & 54.81 & 0 & 0 & 25.4 & 65.93 & 0 \\
2 & 1 & 3.18 & 54.81 & 0 & 0 & 25.4 & 65.93 & 0 \\
3 & 2 & 3.18 & 54.81 & 7.77 & 48.1 & 25.4 & 65.93 & 0.88 \\
4 & 2 & 3.18 & 54.81 & 7.77 & 48.1 & 25.4 & 65.93 & 0.88 \\
5 & 3 & 3.18 & 53 & 14.01 & 95.5 & 25.4 & 159.3 & 1.80 \\
6 & 3 & 3.18 & 53 & 14.01 & 95.5 & 25.4 & 159.3 & 1.80 \\
\hline
\end{tabular}


Fig. 9 Peak acceleration versus mass ratio for aluminum cantilever beam tests

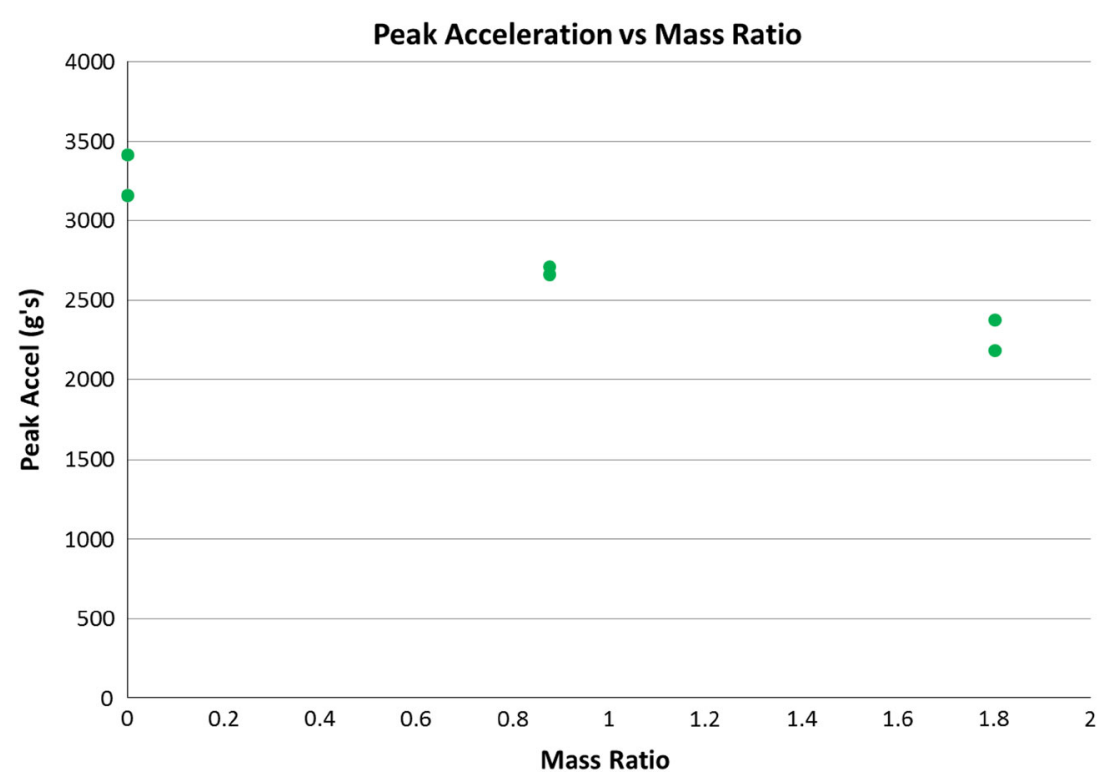

Table 6 Test matrix for polyurea coated can study

\begin{tabular}{llllllllllll}
\hline $\begin{array}{l}\text { Test } \\
\text { number }\end{array}$ & $\begin{array}{l}\text { Charge } \\
\text { mass }(\mathrm{g})\end{array}$ & $\begin{array}{l}\text { DOB } \\
(\mathrm{mm})\end{array}$ & $\begin{array}{l}\text { SOD } \\
(\mathrm{mm})\end{array}$ & $\begin{array}{l}\text { \# of } \\
\text { cylinders }\end{array}$ & $\begin{array}{l}\text { Cylinder } \\
\text { material }\end{array}$ & $\begin{array}{l}\text { Cylinder } \\
\text { OD }(\mathrm{mm}) *\end{array}$ & $\begin{array}{l}\text { Cylinder } \\
\text { ID }(\mathrm{mm}) *\end{array}$ & $\begin{array}{l}\text { Cylinder } \\
\text { height } \\
(\mathrm{mm}) *\end{array}$ & $\begin{array}{l}\text { Total } \\
\text { cylinder } \\
\text { mass }(\mathrm{g})\end{array}$ & $\begin{array}{l}\text { Polyurea } \\
\text { mass }(\mathrm{g})\end{array}$ & $\begin{array}{l}\text { Mass ratio } \\
(\text { Poly/Alum) }\end{array}$ \\
\hline 2 & 2.2 & 10 & 40 & 1 & Aluminum & 66 & 65.8 & 38.1 & 3.07 & 0 & 0.00 \\
3 & 2.2 & 10 & 40 & 1 & Aluminum & 66 & 65.8 & 38.1 & 2.89 & 0 & 0.00 \\
4 & 2.2 & 10 & 40 & 1 & Aluminum & 66 & 65.8 & 38.1 & 6.95 & 3.88 & 1.27 \\
5 & 2.2 & 10 & 40 & 1 & Aluminum & 66 & 65.8 & 38.1 & 7.1 & 4.03 & 1.32 \\
6 & 2.2 & 10 & 40 & 1 & Aluminum & 66 & 65.8 & 38.1 & 10.65 & 7.58 & 2.48 \\
7 & 2.2 & 10 & 40 & 1 & Aluminum & 66 & 65.8 & 38.1 & 11.28 & 8.21 & 2.68 \\
10 & 2.2 & 10 & 40 & 1 & Aluminum & 66 & 65.8 & 38.1 & 18.12 & 15.05 & 4.92 \\
11 & 2.2 & 10 & 40 & 1 & Aluminum & 66 & 65.8 & 38.1 & 18.75 & 15.68 & 5.12 \\
\hline
\end{tabular}

Values reported with an $*$ denote those takes of the shim stock cylinder before the coated in polyurea

acceleration decreases as the mass of polyurea applied to the cylinder increases. The second is that the time over which the acceleration pulse is delivered stretches out as the mass of the coat increases. So though the acceleration signal is lower, it is delivered over a significantly larger period of time.

It is helpful also to view the final deformed state of each of the experimental scenarios. At the end of each experiment, the cylinder was detached from the hull and compared with the other deformed cylinders. It was noted that as the mass of the polyurea coating increased, the recovered height of the cylinder also increased. A visual of the final cylinder deformations (post-experiment) is presented in Fig. 13.

From Fig. 13 it is clearly seen that as the mass of polyurea applied to the aluminum base increases, the final deformation of the can decreases. It should be noted that each cylinder underwent severe crushing in every experiment. After the initial crushing, the cylinders with the polyurea coating rebounded and recovered a portion of their initial height. There was no delamination of polyurea from the metal substrate noted in the thinner coats, and only minor delamination of the polyurea from the aluminum as the mass of the polyurea increased. A measurement of the height of the crushed cylinder was made in each scenario and averaged to determine how much height each cylinder recovered after the blast event. These results along with the peak acceleration are plotted against the mass ratio of polyurea to aluminum of each cylinder in Fig. 14.

From viewing the graph a few observation can be made. The first and most important is how much of a decline in acceleration is obtained by coating thin-walled cylinders with polyurea. Note from Fig. 14 that by adding the mass of the metal substrate in the form of a polyurea coating (resulting in a 1:1 mass ratio), the acceleration levels of the frame can be reduced by $30 \%$ of the value experienced by the frame that utilized only an uncoated cylinder. Also it should be noted that 


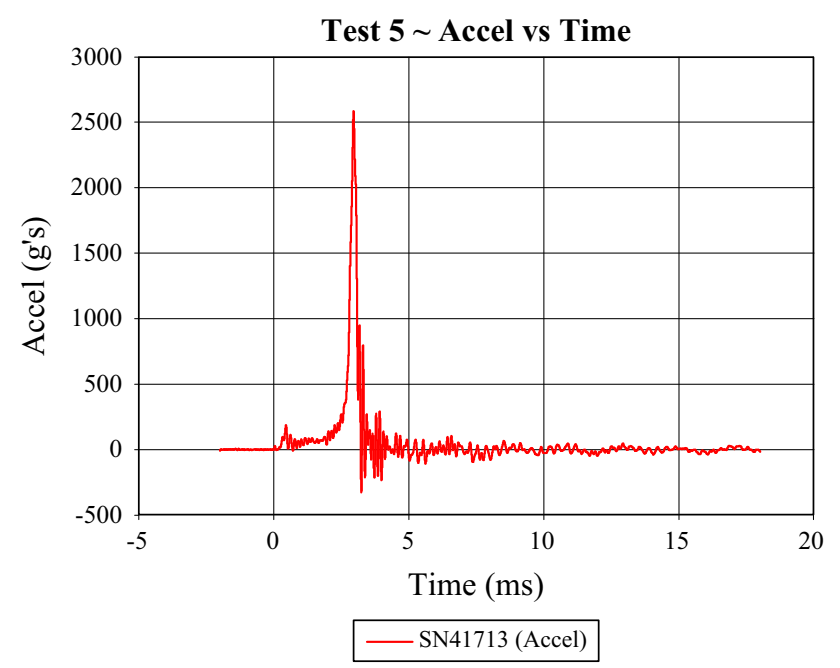

Fig. 10 Acceleration signal from a polyurea coated cylinder experiment

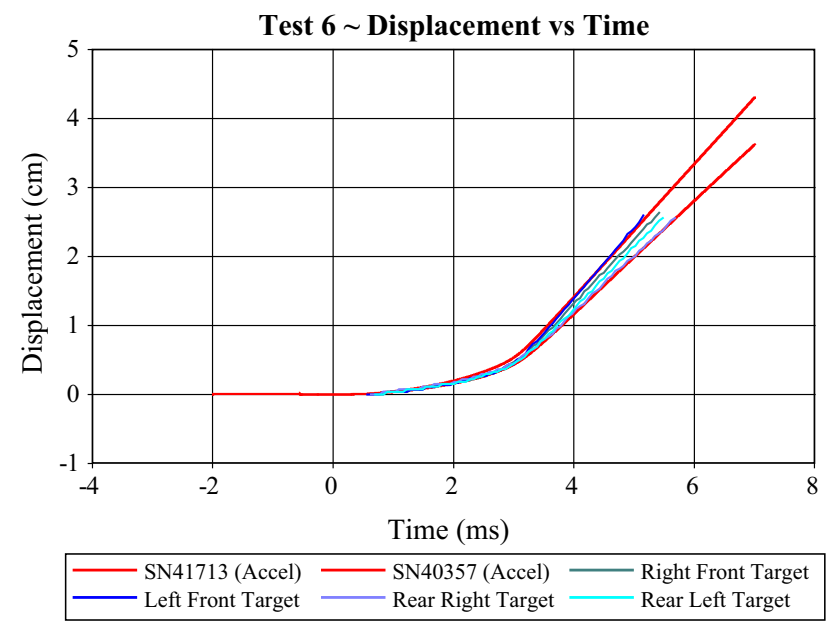

Fig. 11 Accompanying displacement versus time curve comparison for accelerometer and camera data

the mass of the cylinders is negligible compared to the mass of the hull/frame combination. Though not reported in detail here it was found that increasing the mass ratio on the thin-walled cylinders did not greatly affect the impulse and kinetic energy imparted to the frame.

To develop a better understanding of how all of the polyurea coating results line up, the acceleration values for each series of experiments were normalized by setting the acceleration of the uncoated bar or cylinder as the baseline value, and dividing each acceleration value in the series by the acceleration of each series' respective baseline value. By doing this, a plot was developed that directly compares the effect on acceleration of coating structures in polyurea. This plot is shown in Fig. 15.

In Fig. 15, blue triangles signify the cantilevered beam experiments conducted with steel bars; the red circles
Acceleration Comparison for Coated Cylinders

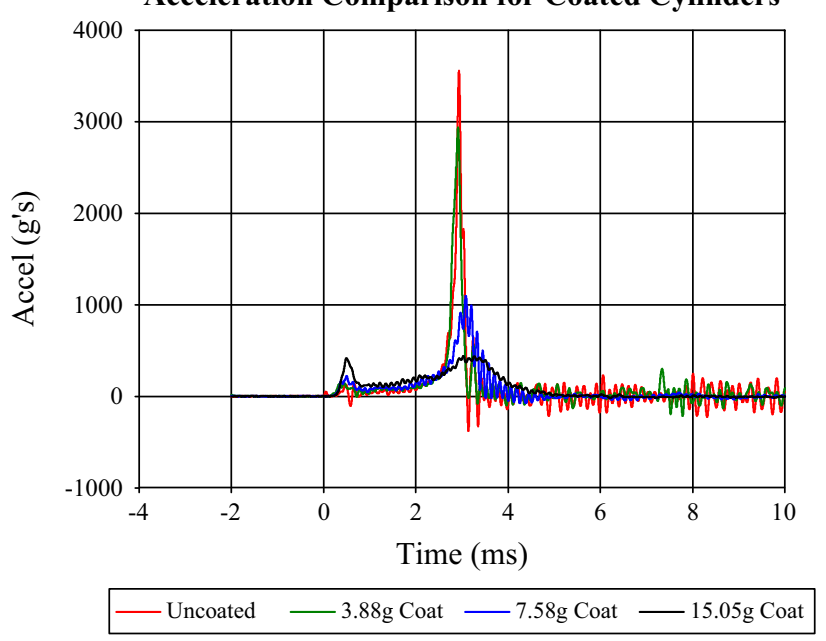

Fig. 12 Acceleration signal comparison for various coatings

represent the thin-walled cylinders which were blast loaded, and green squares show the acceleration value of the aluminum cantilevered beams. From this figure, the conclusion is made that the mass ratio of a coated structure has significant importance when considering the possibility of the coating to have an effect on peak acceleration of a structure. Very small mass ratios may have a detrimental, or no, effect on the ability of a structure to effectively absorb a dynamic load, while a mass ratio greater than one has a positive effect. This result is of significant value as steel plates are a commonly coated material. In order for the coating to have positive effects, an extremely thick coating would have to be applied. On the other hand, when considering very light structures, such as the thin-walled cylinders used in this study, a small amount of polyurea has the potential to have a very large effect.

The final series of experiments was run to study the nonlinear acceleration mitigation benefit of polymeric coated thin-walled cylinders. To this end a series of blast experiments was run where the polyurea to aluminum mass ratio was kept constant (along with the other test parameters such as SOD and DOB) while the charge mass was varied. Experiments with coated and uncoated cylinders were run to compare how the mitigation of acceleration varied as the charge size increased. The test matrix for this series of experiments is shown in Table 7.

A total of 20 experiments were conducted in which the data was usable, eight experiments with cylinders having a polyurea to aluminum mass ratio of about 0.75 and eight experiments with uncoated cylinders. Two experiments were run for each type of cylinder at charge sizes of 0.75 , $1.25,1.75$, and $2.2 \mathrm{~g}$ of explosive. After the mitigation experiments, four more experiments were run with no mitigation present for the purpose of developing a baseline 


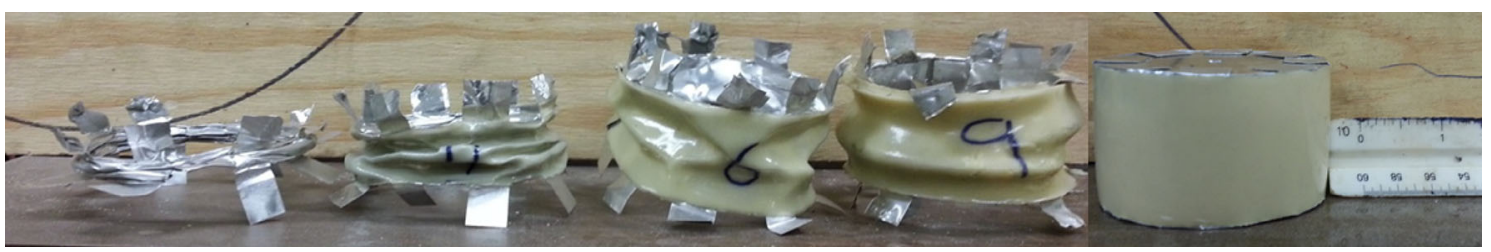

Fig. 13 Front view of crushed cylinders increasing in polyurea mass from left to right

Fig. 14 Trends displaying how peak acceleration of the frame and cylinder recovered height vary as mass ratio increases

Fig. 15 A comparison of normalized peak acceleration versus mass ratio for three different test series
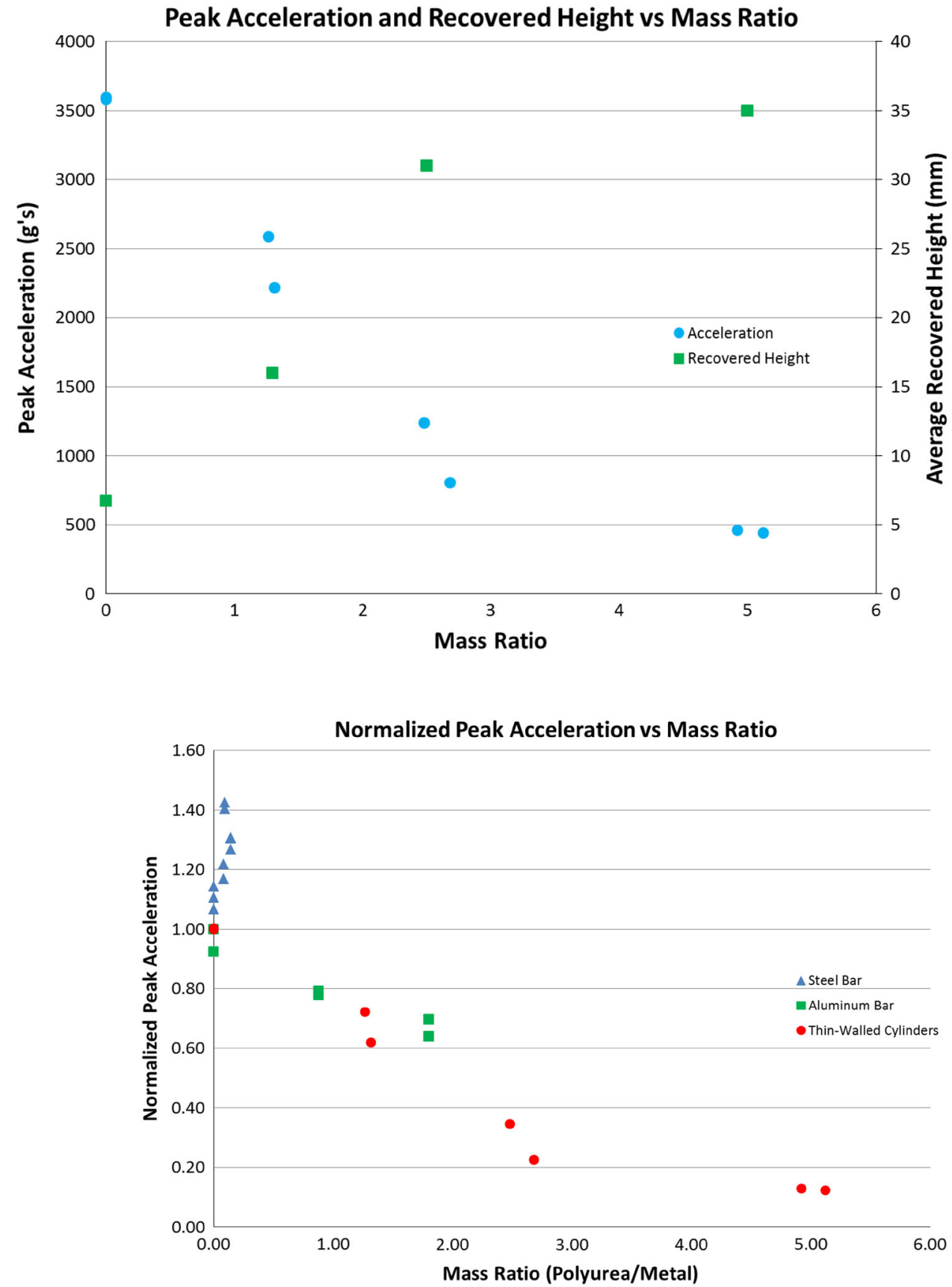

comparison. These baseline experiments were run with an air gap present, with the air gap having the same distance as the cylinders' height.
The round hull/frame plate combination employed in earlier experimentation was used to collect data. In the instances where thin-walled cylinders were examined, a 
single cylinder provided the mitigation. As in the other studies, in order for the data to be reported, the displacement profiles obtained from the high-speed camera and the double integrated accelerometer must match.

At the conclusion of the test series, two plots were created. In Fig. 16, the acceleration of the frame for the three cases (no mitigation, uncoated cylinders, and coated cylinders) is displayed as a function of charge mass. Figure 17 shows the final recovered height of the cylinders.

From Fig. 16 which presents acceleration as a function of charge mass, at $0.75 \mathrm{~g}$ charge mass both the coated and uncoated crushing cylinders result in essentially the same very large reduction in acceleration (more than a tenfold reduction). As the charge mass increases to $1.25 \mathrm{~g}$, the coated cylinders perform in the neighborhood of $5 \%$ more effectively than the uncoated cylinder. As the charge size increases to 1.75 and $2.2 \mathrm{~g}$, the gap between coated and uncoated cylinders moves to around $10 \%$. To clarify, for a $75 \mathrm{~g}$ charge, both the uncoated and coated cylinders act to reduce the acceleration level of the baseline experiment by about $93 \%$. For the $1.25 \mathrm{~g}$ charge, the uncoated cylinder reduces the base acceleration by $90 \%$ while the polyurea coated cylinder reduces the baseline by about $95 \%$. For the
$1.75 \mathrm{~g}$ charge the uncoated cylinder results in a $64 \%$ reduction compared with a $74 \%$ reduction for the coated cylinder. Finally, with a 2.2 g charge, the uncoated cylinder acts to eliminate $47 \%$ of the baseline acceleration while the coated cylinder eliminates $57 \%$.

Looking at Fig. 17, it is seen that as charge mass increases, the recovered height of the polymeric cylinder is steadily greater than the uncoated can. During maximum crushing scenarios, coated cylinders will recover to around a $13 \mathrm{~mm}$ height as compared with uncoated cylinders which only recover to around a seven millimeter final height.

\section{Discussion}

The series of experiments run in this paper illuminated some very interesting dynamic behavior of materials. Initially, a series of cantilevered beam experiments were run where the mass and thickness of the steel beam was held constant while an increasing mass and thickness of polyurea coating was applied to the steel. A second series of experiments varied the mass ratio of the polyurea coat to

Table 7 Test matrix for nonlinear study

\begin{tabular}{|c|c|c|c|c|c|c|c|c|c|c|c|}
\hline $\begin{array}{l}\text { Test } \\
\text { number }\end{array}$ & $\begin{array}{l}\text { Charge } \\
\text { mass (g) }\end{array}$ & $\begin{array}{l}\text { DOB } \\
(\mathrm{mm})\end{array}$ & $\begin{array}{l}\text { SOD } \\
(\mathrm{mm})\end{array}$ & $\begin{array}{l}\text { \# of } \\
\text { cylinders }\end{array}$ & $\begin{array}{l}\text { Cylinder } \\
\text { material }\end{array}$ & $\begin{array}{l}\text { Cylinder OD } \\
\text { before coat } \\
(\mathrm{mm})^{*}\end{array}$ & $\begin{array}{l}\text { Cylinder } \\
\text { ID }(\mathrm{mm})^{*}\end{array}$ & $\begin{array}{l}\text { Cylinder } \\
\text { height } \\
(\mathrm{mm})^{*}\end{array}$ & $\begin{array}{l}\text { Cylinder } \\
\text { mass }(\mathrm{g})^{*}\end{array}$ & $\begin{array}{l}\text { Polyurea } \\
\text { mass }(g)\end{array}$ & $\begin{array}{l}\text { Mass } \\
\text { ratio } \\
(\mathrm{P} / \mathrm{S})\end{array}$ \\
\hline 1 & 2.2 & 10 & 40 & 1 & Aluminum & 66 & 65.8 & 38.1 & 3 & 2.37 & 0.79 \\
\hline 2 & 2.2 & 10 & 40 & 1 & Aluminum & 66 & 65.8 & 38.1 & 3 & 2.58 & 0.86 \\
\hline 3 & 1.75 & 10 & 40 & 1 & Aluminum & 66 & 65.8 & 38.1 & 3 & 2.75 & 0.92 \\
\hline 4 & 1.75 & 10 & 40 & 1 & Aluminum & 66 & 65.8 & 38.1 & 3 & 2.02 & 0.67 \\
\hline 5 & 1.25 & 10 & 40 & 1 & Aluminum & 66 & 65.8 & 38.1 & 3 & 2.63 & 0.88 \\
\hline 6 & 1.25 & 10 & 40 & 1 & Aluminum & 66 & 65.8 & 38.1 & 3 & 2.27 & 0.76 \\
\hline 7 & 0.75 & 10 & 40 & 1 & Aluminum & 66 & 65.8 & 38.1 & 3 & 2.46 & 0.82 \\
\hline 8 & 0.75 & 10 & 40 & 1 & Aluminum & 66 & 65.8 & 38.1 & 3 & 2.47 & 0.82 \\
\hline 9 & 0.75 & 10 & 40 & 1 & Aluminum & 66 & 65.8 & 38.1 & 3 & 0 & 0.00 \\
\hline 10 & 0.75 & 10 & 40 & 1 & Aluminum & 66 & 65.8 & 38.1 & 3 & 0 & 0.00 \\
\hline 11 & 1.25 & 10 & 40 & 1 & Aluminum & 66 & 65.8 & 38.1 & 3 & 0 & 0.00 \\
\hline 12 & 1.25 & 10 & 40 & 1 & Aluminum & 66 & 65.8 & 38.1 & 3 & 0 & 0.00 \\
\hline 13 & 1.75 & 10 & 40 & 1 & Aluminum & 66 & 65.8 & 38.1 & 3 & 0 & 0.00 \\
\hline 14 & 1.75 & 10 & 40 & 1 & Aluminum & 66 & 65.8 & 38.1 & 3 & 0 & 0.00 \\
\hline 15 & 2.2 & 10 & 40 & 1 & Aluminum & 66 & 65.8 & 38.1 & 3 & 0 & 0.00 \\
\hline 16 & 2.2 & 10 & 40 & 1 & Aluminum & 66 & 65.8 & 38.1 & 3 & 0 & 0.00 \\
\hline 24 & 2.2 & 10 & 40 & - & $\begin{array}{l}\text { No } \\
\quad \text { mitigation }\end{array}$ & - & - & - & - & - & - \\
\hline 26 & 1.75 & 10 & 40 & - & $\begin{array}{l}\text { No } \\
\text { mitigation }\end{array}$ & - & - & - & - & - & - \\
\hline 35 & 0.75 & 10 & 40 & - & $\begin{array}{l}\text { No } \\
\quad \text { mitigation }\end{array}$ & - & - & - & - & - & - \\
\hline 36 & 1.25 & 10 & 40 & - & $\begin{array}{l}\text { No } \\
\quad \text { mitigation }\end{array}$ & - & - & - & - & - & - \\
\hline
\end{tabular}


Fig. 16 Difference in peak acceleration between coated and uncoated cans versus charge mass

Fig. 17 Final recovered height of the blast loaded cylinder versus charge mass
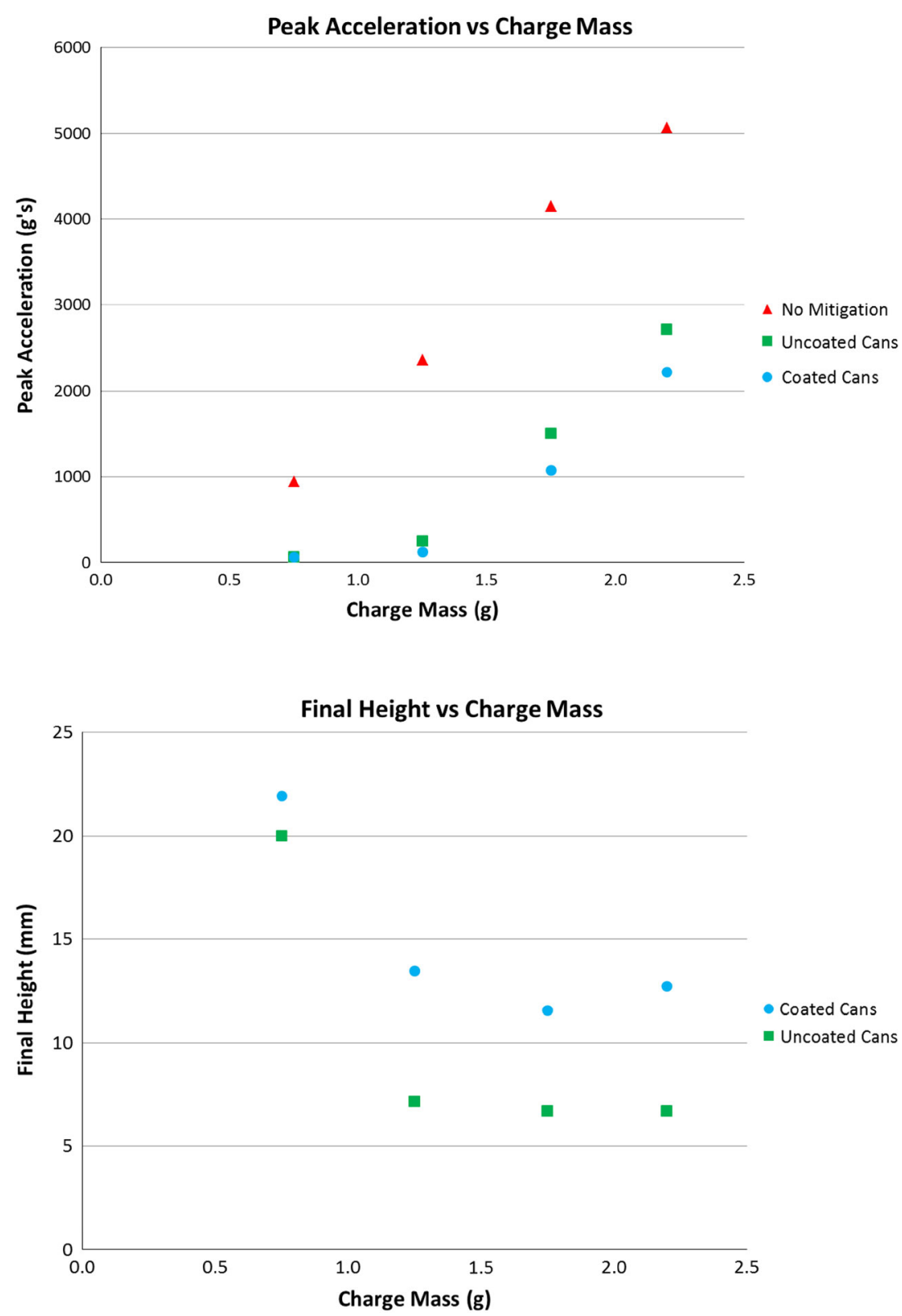

steel substrate while holding the mass constant. Finally, a series of experiments was run using a thin aluminum beam with an equivalent (in terms of mass) amount of polyurea applied as a coating. The analysis of the results of these three series of tests showed that for elastic response of dynamically loaded structures, mass ratio plays an important role. Specifically, it was seen that in order for a polyurea coating to have a benefit on acceleration levels, a mass ratio on the order of the mass of the metal substrate must be applied. This level of coating will inherently increase the thickness of the beam as the density of metal is far greater than that of polyurea. This increase in thickness is expected to have some effect on the dynamic behavior of the beam. However, it was shown from the steel beam tests, that it is possible to use the polyurea coating to increase the beam thickness and have no (or negative) effect on the peak acceleration. Because of this, it is reasoned that the primary benefits from using the polyurea coating to mitigate peak acceleration comes from the interaction of the material behavior of the polyurea and metal substrate. It should also be noted that in order to perform a test with equivalent mass ratios of polyurea to metal, we had to switch metal from steel to aluminum-leading to the possibility of a metal material effect on the behavior of the dynamically loaded cantilever beams.

One scenario where an equivalent mass of polyurea can be applied to a metallic structure reasonably is the use of thin-walled cylinders as a mitigation technique. A series of 
experiments was run where various polyurea coatings were applied to a thin-walled aluminum cylinder that was explosively crushed in between two plates. In this application, the benefit on peak acceleration was very obvious. In previous research [22] it is shown that the plastic deformation of the metallic structure mitigates the acceleration levels greatly on its own. In combination with the polyurea coating, this technique performs at an even higher level. From studying pictures of post-blasted cylinders and comparing these to peak acceleration levels, it is easily seen that peak acceleration declines by greater amounts with less plastic deformation of the cylinder. The acceleration mitigation level of crushing cylinders was compared to that of the elastically loaded beam experiments, and it was found that, initially at least, the trend is similar for both cases. This result is somewhat surprising seeing that the material behavior is drastically different between the two cases, with high amounts of plastic deformation from the former versus pure elastic response from the latter. It should be noted however, that we did not run experiments on the cantilevered beams out to the mass ratio that we had for the crushing cylinders.

\section{Conclusions}

The broad goal of this research was to develop a better understanding of how the addition of a polymeric coating to dynamically loaded structures increased the structures ability to mitigate acceleration. Some basic studies were performed through the use of polyurea coated steel and aluminum cantilever beams. The cantilever beams were tested dynamically by using a high-pressure gas gun, and produced information leading to the following conclusion. In the elastic range of material response to dynamic loading, thin coats of polyurea have no beneficial effect on the mitigating behavior of the structure. For the beneficial effects of polyurea coatings to appear, the mass ratio of polyurea to metal must be increased to one or higher.

We then investigated polyurea-coated thin-walled cylinders that were crushed between explosively loaded plates. With regards to adding a coating of polyurea to an explosively crushed thin-walled cylinder, large advantages in acceleration mitigation were seen. With a polyurea coating with mass equal to the thin-walled cylinder, the acceleration level was decreased by around $30 \%$. The mass ratio of the polyurea to metal substrate was incrementally increased to 5:1 where a greater than $85 \%$ reduction in acceleration was seen (as compared to a bare metal cylinder). It was found that at higher mass ratios, the acceleration of cantilever beams and explosively loaded plates both show similar decreasing trends as the mass ratio of the polyurea to metal increases.
Finally, it was seen that at low acceleration levels, polyurea coated and uncoated cylinders both mitigate acceleration equally well, even if the final deformation of the coated cylinder was significantly less. As the size of the charge (and thus the baseline acceleration) increases, polyurea acts non-linearly to more effectively mitigate the level of acceleration seen by the frame.

\section{References}

1. Fiskum G, Hazelton J, Gullapalli R, Fourney WL (2010) Animal model of mild brain injury caused by blast-induced hyperacceleration relevant to IED-targeted military vehicles

2. Nelson NW, Lamberty GJ, Sim AH, Doane BM (2012) Blast from the past and present: a review of blast-related injury in military personnel and veterans. In: Neuropsychological practice with veterans. p. 145

3. Fourney WL, Leiste U, Bonenberger R, Goodings DJ (2005) Mechanism of loading on plates due to explosive detonation. Fragblast 9(4):205-217

4. Taylor LC, Fourney WL, Leiste U, Genson K (2008) Geometrical shaping of vehicles for reducing impulse from buried explosions. In: Joint classified bombs/warheads \& ballistics symposium, Monterey, CA

5. Benedetti R, Fourney WL (2010) Mitigation of loading on floorboards in light armored vehicles subjected to explosive loading. University of Maryland, College Park

6. Leiste U, Fourney WL, Duff T (2013) Experimental studies to investigate pressure loading on target plates. Blast Fragm 7(2):99-126

7. Alghamdi AAA (2001) Collapsible impact energy absorbers: an overview. Thin Walled Struct 39(2):189-213

8. Yuen SC, Nurick GN (2008) The energy-absorbing characteristics of tubular structures with geometric and material modifications: an overview. Appl Mech 61(2):020802

9. Gupta NK, Sekhon GS, Gupta PK (2005) Study of lateral compression of round metallic tubes. Thin Walled Struct 43(6):895-922

10. Shim VPW, Stronge WJ (1986) Lateral crushing in tightly packed arrays of thin-walled metal tubes. Int J Mech Sci 28(10):709-728

11. Gupta NK, Velmurugan R (1997) An analysis of axial crushing of composite tubes. J Compos Mater 31(13):1262-1286

12. Palanivelu S, Paepegem WV, Degrieck J, Vantomme J, Kakogiannis D, Ackeren JV, Hemelrijck DV, Wastiels J (2010) Comparison of the crushing performance of hollow and foamfilled small-scale composite tubes with different geometrical shapes for use in sacrificial cladding structures. Composites B 41(6):434-445

13. Palanivelu S, Van Paepegem W, Degrieck J, Van Ackeren J, Kakogiannis D, Van Hemelrijck D, Wastiels J, Vantomme J (2010) Experimental study on the axial crushing behavior of pultruded composite tubes. Polym Test 29(2):224-234

14. Palanivelu S, Van Paepegem W, Degrieck J, Reymen B, Ndambi JM, Vantomme J, Kakogiannis D, Wastiels J, Hemelrijck DV (2011) Close-range blast loading on empty recyclable metal beverage cans for use in sacrificial cladding structure. Eng Struct 33(6): 1966-1987

15. Theobald MD, Nurick GN (2007) Numerical investigation of the response of sandwich-type panels using thin-walled tubes subject to blast loads. Int J Impact Eng 34(1):134-156

16. Theobald MD, Nurick GN (2010) Experimental and numerical analysis of tube-core claddings under blast loads. Int $\mathrm{J}$ Impact Eng 37(3):333-348 
17. Yi J, Boyce MC, Lee GF, Balizer E (2006) Large deformation rate-dependent stress-strain behavior of polyurea and polyurethanes. Polymer 47(1):319-329

18. Roland CM, Twigg JN, Vu Y, Mott PH (2007) High strain rate mechanical behavior of polyurea. Polymer 48(2): 574-578

19. Tekalur SA, Shukla A, Shivakumar K (2008) Blast resistance of polyurea based layered composite materials. Compos Struct 84(3):271-281

20. Ackland K, Anderson C, Ngo TD (2013) Deformation of polyurea-coated steel plates under localized blast loading. Impact Eng 51:13-22

21. Brodrick T, Hurley R, Fourney WL (2014) Mitigation of loading on personnel in light-armored vehicles using small model testing. Blast mitigation. Springer, New York, pp 249-277
22. Bonsmann JM (2013) Small scale testing to study mitigation of acceleration on simulated vehicles. Dissertation, University of Maryland, College Park

23. Bonsmann JM, Fourney WL (2012) An examination of the factors affecting the loading on a vehicle subjected to the detonation of a buried mine. Blast Fragm 6(3):155-180

24. HM-VK Ultra high strength handmix polyurea elastomer (2013). http://www.specialty-products.com/pdf/tech-data/polyurea/HM-VK \%20Preliminary.pdf. Accessed Aug 262013

25. Gardner N, Wang E, Kumar P, Shukla A (2012) Blast mitigation in a sandwich composite using graded core and polyurea interlayer. Exp Mech 52(2):119-133

26. LeBlanc J, Gardner N, Shukla A (2013) Effect of polyurea coatings on the response of curved E-glass/vinyl ester composite panels to underwater explosive loading. Composites B 44(1):565-574 